\title{
Residency programs grapple with new Indigenous cultural safety training requirement
}

\author{
口 Cite as: CMAJ 2018 June 25;190:E778-9. doi: 10.1503/cmaj.109-5616
}

Posted on cmajnews.com on June 6, 2018.

$\mathrm{T}$ he Royal College of Physicians and Surgeons of Canada will soon require all residency programs to provide Indigenous health and cultural safety training. Few programs are prepared or know what that training should include, according to medical educators at the recent Indigenous Health Conference in Toronto.

Indigenous people often face racism and ignorance in health care and medical education. "The health statistics for Indigenous people are horrendous, and it's the result of discrimination and neglect over hundreds of years of colonization," said Dr. Anna Banerji, director of global and Indigenous health for continuing professional development at the University of Toronto. "The path to reconciliation will not be an easy one and many non-Indigenous people are afraid of making mistakes. Instead of fearing, let's embrace it."

British Columbia has led the way, introducing cultural safety training for health workers to help them better understand Indigenous culture and provide more sensitive care. Other provinces are following suit, but medical education has been slower on the uptake. Most trainees have "zero" awareness of the history and health impacts of colonization, let alone their own harmful biases, said Dr. Jason Pennington, an assistant professor of general surgery at the University of Toronto. As for faculty, "sometimes they're actually even worse than zero."

Medical students may receive basic training on Indigenous health during undergraduate education but it varies by institution. Few residency programs offer any cultural safety training. If they do, it's usually optional or lumped together with global health topics. Indigenous trainees are often called on to teach their cultures without compensation or support.

It's not clear what shape the new required training will take, said Banerji. "There are a lot of online cultural safety programs right now. Is that enough? Do we need to build our own? Should it be in person?" At the University of Toronto, "we really haven't started," she said. "We're just exploring right now."

Several speakers stressed the importance of teaching medical residents the historical context of poor Indigenous health outcomes. "That's a topic that could be shared amongst all residency programs, that foundation, because we weren't taught that in high school," said Dr. Sarah Funnell, cochair of the College of

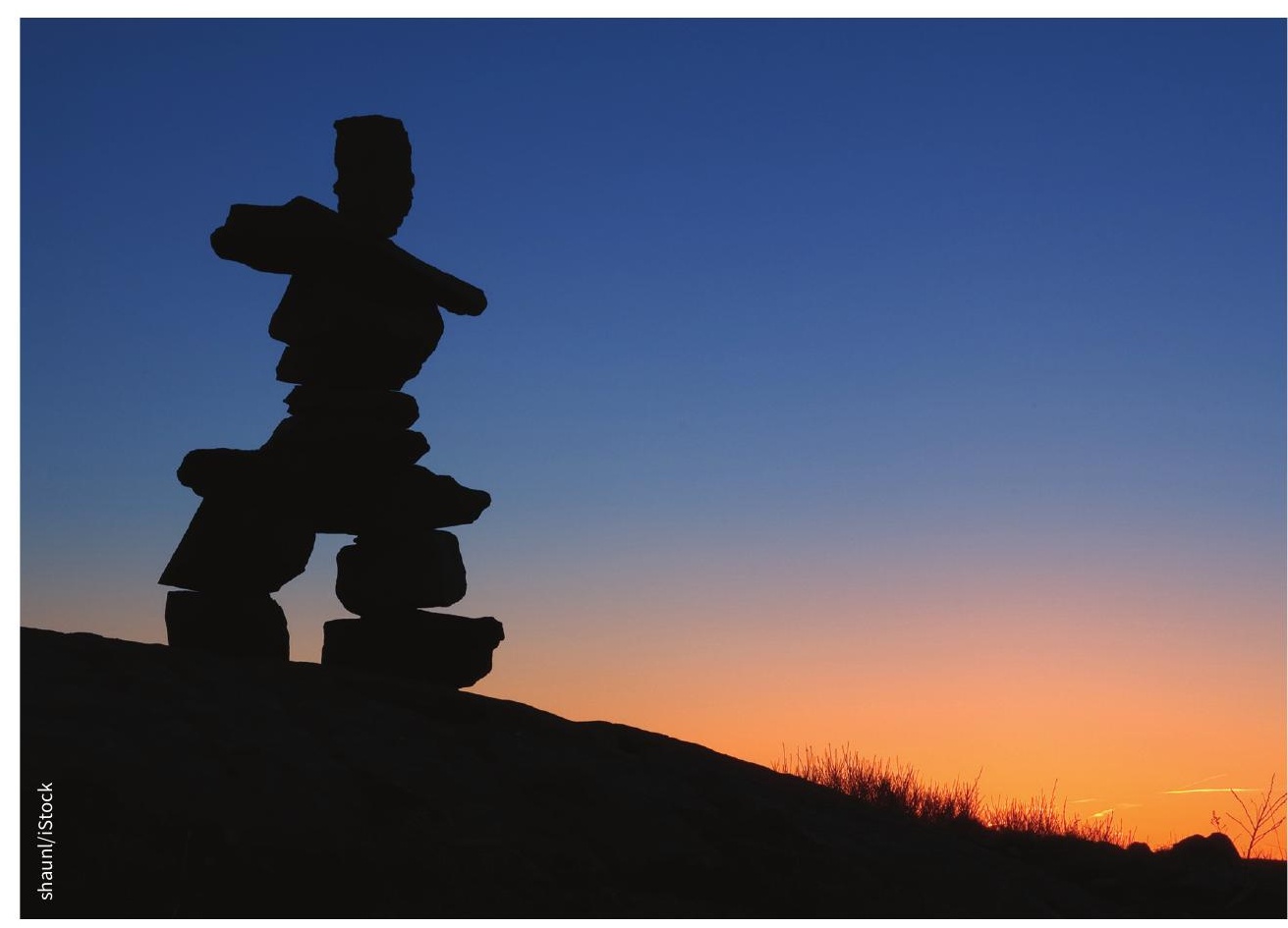

Making health care culturally safer starts with anti-racism training for young doctors, say Indigenous medical educators.
Family Physicians of Canada's Indigenous health working group. She delivered the first mandatory half-day session on Indigenous health for family medicine residents at the University of Ottawa. "We try to create a safe space where people can ask those questions they're afraid to ask, like 'What about reverse racism?' You can't blame people for asking those questions."

Others emphasized teaching respect and making space for elders and traditional knowledge in training. Pennington noted that suspicion of Indigenous traditional medicine dates to first explorers, who refused tea to cure their scurvy because they feared it was witchcraft. Today, "smudging, ceremony, singing and even most of the medicines don't interfere 
with most surgeries I do," he said. "We've got to break down that fear."

Some specialties are further ahead than others. The Canadian Paediatric Society has trained "champions" at most pediatric residency programs to deliver a three-hour presentation on the history, health conditions and cultural differences of Indigenous patients. The downside of this lecture-based model is that residents don't have an opportunity to practise the skills they learn. "I think for residents to get it, we have to do a better job of getting them in touch with Indigenous people," said Dr. Kent Saylor, director of the Indigenous Health Professions Program at McGill University. A more hands-on approach might involve "doing rotations in the communities or working at the urban health centres," he said.

Others cautioned that cultural experiences may backfire unless residents are trained to examine their own biases first. "Sometimes, without doing that, we find people get quite distorted ideas about our cultures," said Diane Smylie, provincial director of the Ontario Indigenous Cultural Safety Program.
Speakers urged that faculty need the same training. They're often the most resistant to cultural safety efforts, explained Bernice Downey, Indigenous Health Initiative lead for McMaster University's faculty of health sciences. "Part of it is fear of making a mistake or offending somebody," she said. More concerning, "they feel they don't have Indigenous people in their class or practice, so it doesn't apply to them. Or they do have Indigenous students who have never said anything, so everything must be fine."

McMaster recently dedicated $\$ 100,000$ to provide external cultural safety training to about 300 senior staff. The medical school also created six working groups to look at reforms to administration, curriculum, support services, research, leadership and incorporation of Indigenous knowledge. Students pushed this change, Downey said. "A small group said that we do not have enough Indigenous curriculum and the faculty is not responding to incidents of racism."

Support from non-Indigenous staff is essential because there are so few Indigenous faculty members. Indigenous com- munities are inundated with calls to consult on training and have limited capacity. In some cases, waiting lists are six or seven months long. Many communities have also been burned by universities in the past, said Downey. "It's been 30 years of trying to negotiate with universities around their own priorities and never being heard, so we have to give time to traditional healers to talk amongst themselves and decide how and what they want to share."

The Royal College is still in the early stages of developing the new Indigenous health and cultural safety training requirements. It is also preparing an Indigenous health primer and funding application to establish a "knowledge hub." According to the Royal College, the initiative will likely take years to implement correctly. "We understand if medical schools are unsure of what to expect at this stage. We don't want to reinvent the wheel, so we are currently collecting information and data to plan the plan, including collating great tools and educational resources currently available."

Lauren Vogel, CMAJ 